\title{
Disruption of a C69-Family Cysteine Dipeptidase Gene Enhances Heat Shock and UV-B Tolerances in Metarhizium acridum
}

\section{OPEN ACCESS}

Edited by:

Marie-Joelle Virolle,

Centre National de la Recherche

Scientifique (CNRS), France

Reviewed by:

Gilberto Úbida Leite Braga University of São Paulo Ribeirão

Preto, Brazil

Nohemi Garcia Ortiz, National Service of Agrifood Health

Safety and Quality, Mexico Yongbo Bao,

Zhejiang Wanli University, China

${ }^{*}$ Correspondence: Yueqing Cao

yueqingcao@cqu.edu.cn Yuxian Xia

yuxianxia@cqu.edu.cn

Specialty section:

This article was submitted to Microbial Physiology and Metabolism, a section of the journal

Frontiers in Microbiology

Received: 12 January 2020 Accepted: 08 April 2020

Published: 05 May 2020

Citation:

Li J, Guo M, Cao Y and Xia Y (2020) Disruption of a C69-Family Cysteine Dipeptidase Gene Enhances Heat Shock and UV-B Tolerances in

Metarhizium acridum

Front. Microbiol. 11:849.

doi: 10.3389/fmicb.2020.00849
Juan Li1,2,3, Mei Guo 1,2,3, Yueqing Cao ${ }^{1,2,3 *}$ and Yuxian Xia ${ }^{1,2,3 *}$

${ }^{1}$ School of Life Sciences, Chongqing University, Chongqing, China, ${ }^{2}$ Chongqing Engineering Research Center for Fungal Insecticides, Chongqing, China, ${ }^{3}$ Key Laboratory of Gene Function and Regulation Technologies, Chongqing Municipal Education Commission, Chongaing, China

In fungi, peptidases play a crucial role in adaptability. At present, the roles of peptidases in ultraviolet (UV) and thermal tolerance are still unclear. In this study, a C69-family cysteine dipeptidase of the entomopathogenic fungus Metarhizium acridum, MaPepDA, was expressed in Escherichia coli. The purified enzyme had a molecular mass of 56-kDa, and displayed a high activity to dipeptide substrate with an optimal Ala-Gln hydrolytic activity at about $\mathrm{pH} 6.0$ and $55^{\circ} \mathrm{C}$. It was demonstrated that MaPepDA is an intracellular dipeptidase localized in the cytosol, and that it is expressed during the whole fungal growth. Disruption of the MaPepDA gene increased conidial germination, growth rate, and significantly improved the tolerance to UV-B and heat stress in $M$. acridum. However, virulence and conidia production was largely unaffected in the $\triangle M a P e p D A$ mutant. Digital gene expression data revealed that the $\triangle M a P e p D A$ mutant had a higher UV-B and heat-shock tolerance compared to wild type by regulating transcription of sets of genes involved in cell surface component, cell growth, DNA repair, amino acid metabolism, sugar metabolism and some important signaling pathways of stimulation. Our results suggested that disruption of the MaPepDA could potentially improve the performance of fungal pesticides in the field application with no adverse effect on virulence and conidiation.

\section{Keywords: entomopathogenic fungi, dipeptidase, heat-shock tolerance, ultraviolet-B tolerance, C69 family}

\section{INTRODUCTION}

The harmful and irreversible impacts of toxic chemical insecticides on the environment are receiving widespread attention and have accelerated extensive research for alternatives, especially biological control agents such as fungi and bacteria (Aw and Hue, 2017). Metarhizium is regarded as reliable substitute for chemical pesticide because of its distinctive advantages, such as safety, environmental friendliness, and low insect resistance (Steven et al., 2003; Jesper et al., 2007; Guerrero-Guerra et al., 2013).

Metarhizium can parasitize multiple insects, such as soil pests, leaf-feeding pests, and pests of cereal grains (Hu et al., 2014; Marion et al., 2016; Hong et al., 2017; Sahayaraj et al., 2018). Previous studies showed that Metarhizium had achieved good results in control of 
fruit fly (Yousef et al., 2017), locust (Peng et al., 2008; BrunnerMendoza et al., 2019), and grasshopper (Milner et al., 2003). Compared with chemical pesticide and other fungal bioagents, such as Beauveria bassiana, and Metarhizium rileyi, Metarhizium anisopliae were more effective to Helicoverpa armigera infection in pigeon peas (Nahar et al., 2004). Combined application of Metarhizium with Bacillus thuringiensis was more effective in controlling pests than single use of $B$. thuringiensis, and the host insects could hardly develop resistance (Tupe et al., 2017). Metarhizium spores were reported to be detected in soil or as endophytes in plants root and can persist over a long time (Greenfield et al., 2016). However, many challenges, such as unstable tolerance to physical and natural conditions and low virulence, limited the efficiency and large-scale application of Metarhizium. Ultraviolet radiation and temperature fluctuations are two noticeable detrimental environmental factors affecting the viability of entomopathogenic fungi for pest control in field (Braga et al., 2015; Fernandes et al., 2015; Ortiz-Urquiza and Keyhani, 2015). Therefore, exploring the mechanism of heat shock and UV-B tolerance would help to improve the efficiency of fungal biocontrol agents by genetic engineering techniques (Zhao et al., 2016).

Peptidases (EC 3.4) are a class of enzymes to hydrolyze peptide chain to oligopeptides and single amino acids (Barrett, 1994). Peptidases can be classified into 261 families by catalytic mechanism as serine, cysteine, aspartyl, threonine, glutamic, or metallopeptidases (Rawlings and Bateman, 2019). For example, peptidases in which the nucleophile that attacks the scissile peptide bond is the sulfhydryl group of a cysteine residue are designated as cysteine-type peptidases (Rawlings et al., 2011; Barrett and Rawlingsm, 2013). The clans and families of cysteine peptidases were summarized in the review (Rawlings and Bateman, 2019).

Peptidases broadly exist in all organisms, playing a key role in the process of cell growth metabolism. Fungi produce extracellular peptidases to break down environmental protein and polypeptides and supply small molecules for fungal growth (St. Leger et al., 1997; James, 2006; Hamin Neto et al., 2018). The spectrum of these secreted peptidases were correlated with the fungal traits, making them possible markers of fungal ecology (Semenova et al., 2017). Serine proteases are essential for pathogenic fungi to utilize environmental nutrients and maintain their own reproduction (dos Santos et al., 2006). Extracellular peptidases play vital role in penetrating insect cuticle and contribute to pathogenicity of fungi (St. Leger, 1995; St. Leger et al., 1997; Yike, 2011; Semenova et al., 2020). Their vital roles in pathogenicity make them become markers of pathogenicity in fungi (Semenova et al., 2020). In human fungal pathogens, secreted peptidase increased the fungal survival and virulence in Aspergillus fumigatus (Beauvais et al., 1997), Cryptococcus neoformans (Clarke et al., 2016) and Candida (Dutton et al., 2016). In thermophilic fungi, peptidases improved their adaptations to high temperature, providing them with adequacy for biotechnological application (de Oliveira et al., 2018).

The dipeptidase (PepD) is an enzyme that cleaves dipeptides into two amino acids (EC 3.4.13). Up to now, few dipeptidases have been assayed and characterized. In Saccharomyces cerevisiae, Duglp, a Cys-Gly-specific dipeptidase regulated the fungi-specific alternative pathway of glutathione degradation (Kaur et al., 2012). In human pathogenic fungus Histoplasma capsulatum, $N$-acetylated $\alpha$-linked acidic dipeptidase performed as a major antigen during histoplasmosis (Toyotome et al., 2015). Dipeptidase A (PepDA) belongs to the cysteine peptidase family C69, which was evolutionarily conserved and found in 14 bacterial phyla and some eukaryotes. In fungi, the PepDA only existed in ascomycetes (Rawlings and Bateman, 2019). Family C69 dipeptidase was first characterized in Lactobacillus farciminis, showing an extremely strict substrate specificity (Sakamoto et al., 2013). Functional analysis revealed that the PepDA did not affect the growth in Lactobacillus helveticus (Dudley et al., 1996). Up to now, the functions and enzyme characteristics of C69 family dipeptidase are rarely understood in filamentous fungi.

In this study, we performed experiments to characterize the function of a C69 family dipeptidase gene MaPepDA in some important biocontrol traits by gene disruption in $M$. acridum. We found that MaPepDA was localized in cytoplasm. Disruption of the MaPepDA gene increased conidial germination, UV-B tolerance and heat-shock tolerance in $M$. acridum. Digital gene expression profiling (DGE) results showed that the MaPepDA affected the transcription of genes involved in cell surface component, cell growth, DNA repair, amino acid metabolism and sugar metabolism. Exceptionally, virulence was largely unaffected in $\triangle M a P e p D A$ mutant.

\section{MATERIALS AND METHODS}

\section{Strains and Growth Conditions}

The fungal wild-type (WT) strain of $M$. acridum CQMa102 was stored in the China General Microbiological Culture Collection Center (CGMCC; No. 0877). The mutant $\triangle$ MaPepDA described in this study was constructed by disruption of the MaPepDA gene from wild-type strain. All fungal strains used in this study were grown on one-quarter-strength Sabouraud's dextrose agar medium (1/4 SDAY consisting of $1 \%$ dextrose, $0.25 \%$ mycological peptone, $0.5 \%$ yeast extract, and $2 \%$ agar, w/v) at $28^{\circ} \mathrm{C}$ for 15 days to obtain mature conidia unless specifically states. The Escherichia coli strains DH5 and BL21 (TransGen Biotech, Beijing, China) were used for cloning experiments and protein expression, respectively. The bacterial strains were cultured at $37^{\circ} \mathrm{C}$ in Luria-Bertani (LB) with vigorous shaking. Agrobacterium tumefaciens AGL-1 was used for fungal transformations. The plasmid pET-28a (+) (Novagen, Madison, WI, United States) was used for protein expression.

\section{Molecular Cloning and Phylogenetic Analysis}

Genomic DNAs were isolated from mycelium using DNA Extraction Kit (OMEGA, Georgia, United States). Fungal total RNAs were extracted from mycelia using RNA Extraction Kit (CWBIO, Beijing, China). Complementary DNA (cDNA) synthesis was performed following the manufacturer's 
instructions of the PrimeScript ${ }^{\mathrm{TM}}$ RT reagent Kit with gDNA Eraser (Perfect Real Time) Kit (TaKaRa, Dalian, China). The whole cDNA sequence of MaPepDA was amplified using primers MaPepD-CF and MaPepD-CR (Supplementary Table S1). The pMD19-T vector was used for cDNA sequencing (TaKaRa, Dalian, China).

\section{Gene Disruption and Complementation}

DNA cassettes for the targeted MaPepDA gene disruption were generated using homologous recombination technique. The disruption vector $\mathrm{pK} 2-\mathrm{PB}-\mathrm{MaPepD}$ was including a 1.1$\mathrm{kb} 5^{\prime}$-flanking sequence and a 0.8 -kb $3^{\prime}$-flanking sequence of the MaPepDA gene. The two fragments were amplified with LF/LR and RF/RR (Supplementary Table S1) and then inserted into the pK2-PB vector (Cao et al., 2014). The pK2-bar-MaPepD was transformed into WT $M$. acridum via Agrobacterium tumefaciens-mediated transformation, and transformants were screened according to previously described method (dos Reis et al., 2004). Two primer pairs of MaPepDVF/LB-PT-R (Supplementary Table S1) and RB-Bar-F/MaPepDVR (Supplementary Table S1) were used to verify the correct insertion of pK2-PB-MaPepD. The complementation vector $\mathrm{pK} 2$-sur-MaPepD:Enhanced green fluorescence protein (EGFP) contained a $3.5-\mathrm{kb}$ fragment including the $1.5-\mathrm{kb}$ $M a P e p D A$ gene coding sequence and the $2.0-\mathrm{kb}$ promoter region, which was amplified with primer pair MaPepD-CP-F/MaPepDCP-R (Supplementary Table S1). The $\mathrm{pK}_{2}$-sur-MaPepD:egfp vector were transformed into $\triangle M a P e p D A$. Transformants were screened on Czapek-Dox medium containing $20 \mu \mathrm{g} / \mathrm{ml}$ chorimuronethyl (Sigma, Bellefonte, PA, United States) and confirmed by Southern blotting. Probe preparation (PF/PR) and blotting was performed according to the instructions of High Prime DNA Labeling and Detection Starter Kit I (Roche, Mannheim, Germany).

\section{Protein Subcellular Localization and Gene Transcription}

The subcellular localization of MaPepDA was determined in complemented strains (CP) in which the MaPepDA was fused with an egfp gene. Total RNAs were extracted from wild strain culture after growing $1,3,6,9,12,15$ day on 1/4 SDAY. Transcription level of the MaPepDA gene was determined by qRT-PCR with primer QF/QR (Supplementary Table S1) using a SYRB Premix Ex Taq $^{\mathrm{TM}}$ II kit (TaKaRa, Dalian, China) according to the manufacturer's instructions. The method of 2$(\Delta \Delta \mathrm{Ct})$ was employed to calculate the relative gene expression levels (Livak and Schmittgen, 2001). The glyceraldehyde-3phosphate dehydrogenase gene Magpd (gpdF/gpdR, EFY84384) was employed to normalize the amount of template cDNA in each reaction. Data were expressed as the mean \pm SE (standard error) of three independent experiments.

\section{Growth, Germination, and Conidiation}

Conidial suspensions $(50 \mu \mathrm{l})$ at a concentration of $1 \times 10^{7}$ conidia/ml were spread evenly on $1 / 4$ SDAY plates, and the plates were incubated at $28^{\circ} \mathrm{C}$. Germinated spores were counted every
2 h until control spores germinated almost completely. Percent germination indicated the percentage of germinated spores in a total of 100 randomly selected spores. A spore was considered as germinated when the length of germ tube reached one half of its width (Cao et al., 2014). The determination was conducted in triplicate. The mean 50\% germination time (GT50) was then calculated. Hyphal growth was examined $16 \mathrm{~h}$ post inoculation and photographed under a microscope (Nikon Eclipse Ci-E, Tokyo, Japan). To observe colony morphology, $2 \mu \mathrm{l}$ aliquots of conidial suspension $\left(1 \times 10^{6}\right.$ conidia/ml $)$ was dropped on $1 / 4$ SDAY and the plates were incubated at $28^{\circ} \mathrm{C}$ for 5 days. Conidia production was determined on 1/4 SDAY as described previously (Cao et al., 2014).

\section{Tolerance to Stresses}

Fungal conidia suspensions were dotted on 1/4 SDAY supplemented with the following stressors: $0.01 \%$ sodium dodecyl sulfate (SDS), $200 \mu \mathrm{g} / \mathrm{ml}$ Calcofluor White (CFW), $500 \mu \mathrm{g} / \mathrm{ml}$ congo red, and $6 \mathrm{mmol} / 1 \mathrm{H}_{2} \mathrm{O}_{2}$. Sensitivity to each chemical was represented by relative growth inhibition (RGI), which was determined with the equation $[(\mathrm{Dc}-\mathrm{Dt}) / \mathrm{Dc} \times 100]$, where Dc and Dt indicate the colony diameter of fungal strains under control and stressed conditions, respectively. Tolerance to heat and ultraviolet- $B$ irradiation $\left(1350 \mathrm{~mW} / \mathrm{m}^{2}\right)$ was determined according to previous reports (Rangel et al., 2005; Liu et al., 2010). Following UV and heat treatment, the conidial germination was evaluated after growing $20 \mathrm{~h}$ on $1 / 4$ SDAY. $\mathrm{IT}_{50}$ (time for $50 \%$ inhibition in germination rate by heat or UV irradiation) was calculated with the program GraphPad Prism and compared among WT, $\triangle M a P e p D A$, and CP strains.

\section{Bioassays}

Bioassay was conducted against fifth-instar nymphs of L. migratoria manilensis (Meyen) in two ways. Aliquots $(3 \mu \mathrm{l})$ of conidial suspensions from WT, $\triangle M a P e p D A$, and CP strains were applied topically on the pronotum at a concentration of $1 \times 10^{7}$ conidia/ml in paraffin oil or injected into the hemolymph of locusts at $1 \times 10^{6}$ conidia $/ \mathrm{ml}$ in sterile water. Three groups of 30 locusts for each bioassay were used for each strain. The locusts were fed on fresh corn leaves at $28^{\circ} \mathrm{C}$ and $75 \%$ relative humidity with a 12:12 h light:dark photoperiod. The dead locusts were removed and the number of dead locusts was recorded every $12 \mathrm{~h}$ until all the locusts infected with fungus died. Mean median lethal time $\left(\mathrm{LT}_{50}\right)$ was estimated using the program GraphPad Prism 8.0 and compared among the wild-type, $\triangle M a P e p D A$, and $\mathrm{CP}$ strains. The experiments were conducted three times.

\section{Expression and Purification of Recombinant MaPepDA}

To analyze the enzyme characteristics of MaPepDA, the MaPepDA was expressed in pET-28a carrying a His-tag. To construct the recombinant plasmids of pET-28a-MaPepD-His, The MaPepDA cDNA sequence was amplified with Eo-F/Eo-R (Supplementary Table S1) and inserted into NcoI/XhoI-digested pET-28a $(+)$ vector. The recombinant plasmids amplified in E. coli $\mathrm{DH} 5 \alpha$ were transformed in E. coli BL21, and the 
transformants were screened and cultured on an LB plate supplemented with $50 \mu \mathrm{g} / \mathrm{ml}$ kanamycin at $37^{\circ} \mathrm{C}$ overnight. Single colonies were inoculated into LB containing $50 \mu \mathrm{g} / \mathrm{mL}$ kanamycin, and shaken at $37^{\circ} \mathrm{C}$ for $12 \mathrm{~h}$. This culture $(1 \%, \mathrm{v} / \mathrm{v})$ was then inoculated into $200 \mathrm{ml}$ of LB liquid medium, grew at $37^{\circ} \mathrm{C}$ for $6 \mathrm{~h}$ with $200 \mathrm{rpm}$ and then $500 \mu \mathrm{l}$ isopropylthiogalactoside (IPTG, $500 \mathrm{mM}$ ) was added for induction at $18^{\circ} \mathrm{C}$ for $20 \mathrm{~h}$. Cells were harvested at $12,000 \mathrm{rpm}$ for $2 \mathrm{~min}$ at $4^{\circ} \mathrm{C}$, washed twice with $10 \mathrm{ml}$ of lysis buffer (10 mM HEPES, $10 \mathrm{mM}$ $\mathrm{NaCl} ; \mathrm{pH}$ 7.5). The cells were broken by ultrasonic, and then the lysate was centrifuged at $10,000 \mathrm{rpm}$ for $10 \mathrm{~min}$ at $4^{\circ} \mathrm{C}$. The soluble fraction was analyzed by SDS-Polyacrylamide Gel Electrophoresis (SDS-PAGE).

The recombinant MaPepDA protein (rMaPepDA) was purified using an immobilized nickel-nitrilotriacetic acid (NiNTA) affinity column (GE Healthcare Life Science, Marlborough, United States) with AKTA prime plus (GE Healthcare Life Science, Uppsala, Sweden) (Seo et al., 2007). The purified rMaPepD was analyzed by SDS-PAGE.

\section{Substrate Specificity and Activity Assay}

Substrate specificity of the MaPepDA enzyme was investigated using the cadmium-ninhydrin (Cd-ninhydrin) assay to analyze the hydrolysis of dipeptides (Folkertsma and Fox, 1992). Three dipeptide substrates, Ala-Gln, Gly-Pro, and Leu-Phe were used in substrate specificity and enzyme activity assay. Enzyme solution $50 \mu \mathrm{l}$ and $50 \mu \mathrm{l}$ of substrates $\left(25 \mathrm{mM}\right.$ in $\left.\mathrm{ddH}_{2} \mathrm{O}\right)$ were mixed with $400 \mu \mathrm{l}$ of reaction buffer ( $50 \mathrm{mM}$ Tris- $\mathrm{HCl}$ buffer, $\mathrm{pH} \mathrm{8.0)}$. The reaction mixture was incubated at $37^{\circ} \mathrm{C}$ for $0 \mathrm{~min}, 10 \mathrm{~min}$, $30 \mathrm{~min}, 40 \mathrm{~min}$, and $60 \mathrm{~min}$, respectively. The reaction was terminated by adding $1 \mathrm{ml}$ of $\mathrm{Cd}$-ninhydrin reagent. The mixture was heated at $84^{\circ} \mathrm{C}$ for $5 \mathrm{~min}$ and cooled immediately on ice. The absorbance at $485 \mathrm{~nm}$ was measured (Elsoda et al., 1992). One unit of enzyme activity was defined as the amount of enzyme that increased the absorbance 0.01 per minute under the assay conditions. The protein concentration was measured by Bradford protein assay method with bovine serum albumin (SigmaAldrich, CA, United States) as the standard. The absorbance at $595 \mathrm{~nm}$ was determined with microplate reader (Berthold Technologies, Germany).

To estimate the kinetic parameters of the rMaPepDA, substrates (Ala-Gln, Gly-Pro, and Leu-Phe) were used at concentrations ranging from 12.5-75 mM. Lineweaver-Burk plots (Gobbetti and Fox, 1998) and a Hanes transformation (Hanes, 1983) was used to calculate the Michaelis-Menten constant $\left(K_{\mathrm{m}}\right)$ of the MaPepDA enzyme. Substrates at different concentrations without of MaPepDA enzyme were used as controls. The reaction of mixtures was assayed as described above.

\section{Optimal pH and Temperature of rMaPepDA}

In order to elucidate the influence of $\mathrm{pH}$ on enzymatic activity, the rMaPepDA activity was assayed against Ala-Gln in the $\mathrm{pH}$ range from 4.0 to 8.0 , using the following buffers: maleic acid$\mathrm{NaOH}$ ( $\mathrm{pH} 4.0$ to 6.0 ), PBS ( $\mathrm{pH} 7.0$ ), Tris- $\mathrm{HCl}$ (8.0). Reaction mixtures were incubated at $37^{\circ} \mathrm{C}$ for $30 \mathrm{~min}$. The optimal temperature was determined by analyzing dipeptidase activity at temperatures ranging from $25^{\circ} \mathrm{C}$ to $90^{\circ} \mathrm{C}$ in $50 \mathrm{mM}$ Tris- $\mathrm{HCl}$ buffer ( $\mathrm{pH}$ 8.0). The residual activity was subsequently measured with Ala-Gln as the substrate at pH 8.0 (Sakamoto et al., 2013). The relative activity was defined as the percentage of activity comparing to the highest activity.

\section{Digital Gene Expression Profiling (DGE)}

The total RNAs were extracted from 3-day culture of $\triangle M a P e p D A$ and WT on 1/4 SDAY plate. DGE sequencing was performed using the Illumina HiSeq 2000 at the Beijing Genomics Institute (BGI) (Wuhan, China). Genes with a false discovery rate $($ FDR $)<0.001$ and more than a two-fold change were regarded as differentially expressed genes (DEGs) (Audic and Claverie, 1997). DEGs were classified and annotated using Gene Ontology (GO) analysis and Kyoto Encyclopedia of Genes and Genomes (KEGG) pathway enrichment analysis. To further verify the results of DGE, transcription of 24 differential expressed genes were determined by qRT-PCR with primers listed in Supplementary Table S2.

\section{Statistical Analysis}

The ANOVA one-way model with Date processing System program 22.0 (IBM SPSS Statistical, Chicago, IL, United States) was used to analyze percent germination, conidia yield, $\mathrm{GT}_{50}$, $\mathrm{IT}_{50}, \mathrm{RIG}$, and $\mathrm{LT}_{50}$. Tukey's honest significant difference test was used to separate means at $\alpha=0.05$ or 0.01 .

\section{RESULTS}

\section{MaPepDA Is Conserved Among Fungi}

The protein sequence of MaPepDA (XP_007815714) had 521 amino acids with a predicted molecular weight $57 \mathrm{kDa}$. The multiple sequence alignment analysis showed that the C69 domain of MaPepDA was homologous to C69 family peptidases of other fungal species (Figure 1A). Phylogenetic analysis revealed that MaPepDA was clustered with other PepDA homologs from entomopathogenic fungi (Figure 1B).

In order to analyze the cellular localization of MaPepDA, EGFP-tagged MaPepDA fusion protein under regulation of the native promoter was expressed in $\triangle M a P e p D A$ mutant. Fluorescent microscopic visualization showed that the fusion MaPepDA-EGFP was evenly localized in cytoplasm (Figure 2A), which was consistent with the estimated results of the online program ${ }^{1}$. Time-course analysis of transcription showed that the MaPepDA was expressed during the whole fungal growth (Figure 2B).

\section{Purification and Characterization of rMaPepDA}

The MaPepDA protein was induced with $1 \mathrm{mM}$ IPTG and further purified using a Ni-chelating resin column. Results showed that

${ }^{1}$ http://www.csbio.sjtu.edu.cn/bioinf/Cell-PLoc-2/ 
A

\section{C69-peptidase}

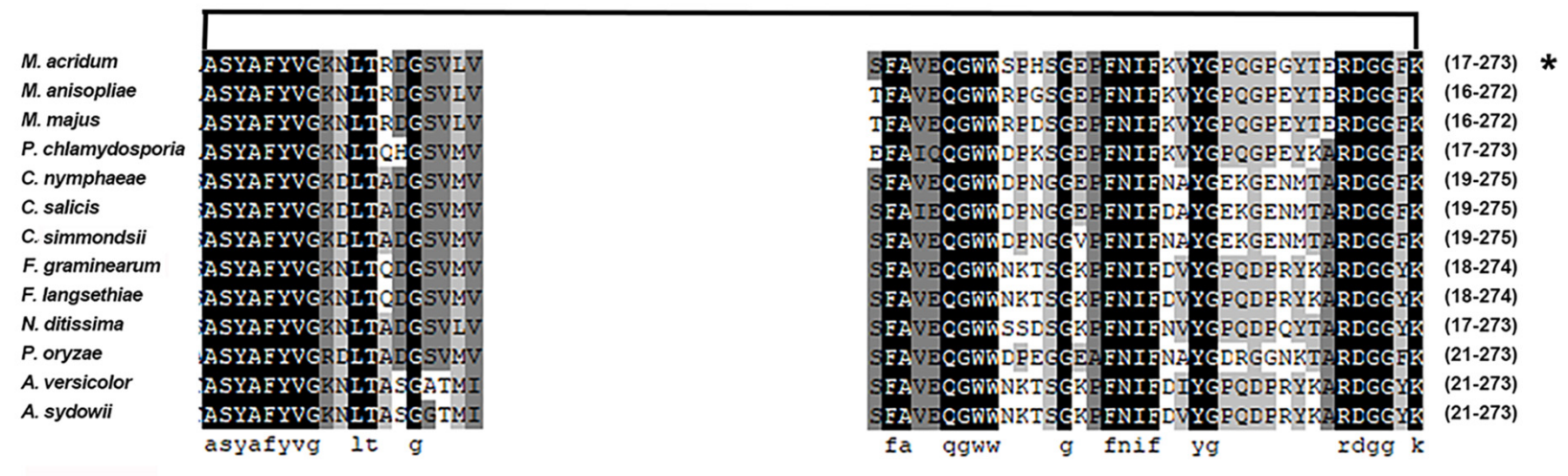

B

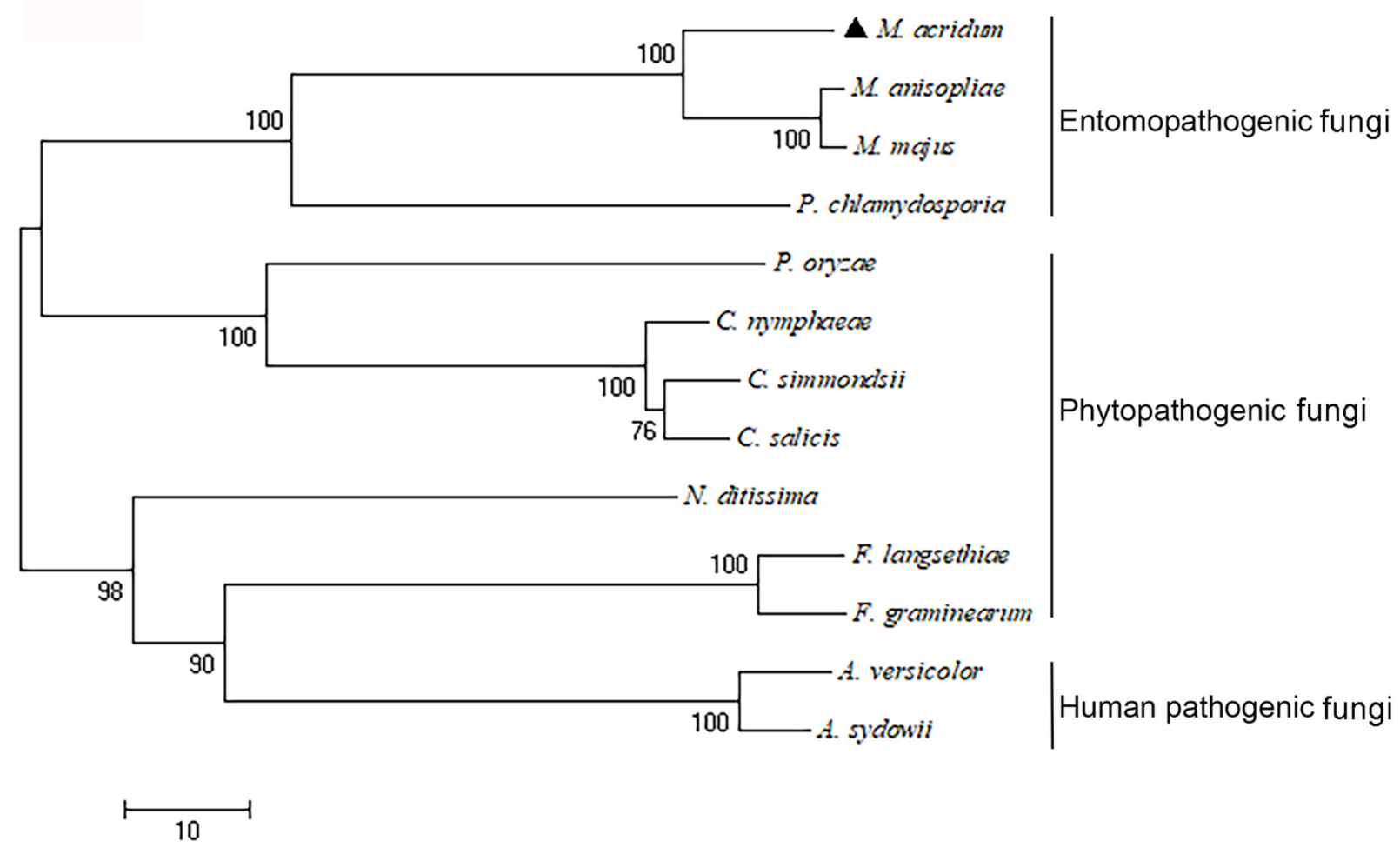

FIGURE 1 | Bioinformatics analysis of the MaPepDA protein. (A) MaPepDA shared conserved domain with other C69 dipeptidase homologs. (B) Phylogenetic analysis of PepDA family proteins from the selected human, plant, and insect fungal pathogens. M. acridum: Metarhizium acridum (XP_007815714); M. majus: Metarhizium majus (KID96910); M. anisopliae: Metarhizium anisopliae (KFG80018); P. chlamydosporia: Pochonia chlamydosporia (XP_018139060); P. oryzae: Pyricularia oryzae (ELQ32800); C. nymphaeae: Colletotrichum nymphaeae (KXH34606); C. simmondsii: Colletotrichum simmondsii (KXH29269); C. salicis: Colletotrichum salicis. (KXH50308); N. ditissima: Neonectria ditissima (KPM38691); F. graminearum: Fusarium graminearum (XP_011328638); F. langsethiae: Fusarium langsethiae (KPA42066); A. sydowii: Aspergillus sydowii (OJJ60401); A. versicolor: Aspergillus versicolor (OJI99730). The full amino acid sequences were aligned with Clustal $X$ and a neighbor joining tree was generated with 1,000 boot strap replicates using the program MEGA v4.0 (Tamura et al., 2007 ). *means the sequence of MaPepDA.

MaPepDA was successfully expressed in E. coli BL21. SDSPAGE showed that MaPepDA-His had a molecular mass of about $59-\mathrm{kDa}$, which was close to the theoretical molecular mass (56 kDa) deduced from the MaPepDA sequence (Figure 3A). The MaPepDA showed high activity when the $\mathrm{pH}$ was in the range
6.0 to $8.0(\geq 74 \%)$ with maximal activity at $\mathrm{pH}$ 6.0. Compared with the activity at $\mathrm{pH} 6.0$, the activity of MaPepDA decreased about $70 \%$ when $\mathrm{pH}$ was 4.0 (Figure 3B). MaPepDA showed a wide thermal resistance ranging from $25^{\circ} \mathrm{C}$ and $70^{\circ} \mathrm{C}$. MaPepDA enzyme activity exhibited about $75 \%$ and $80 \%$ of the maximum 

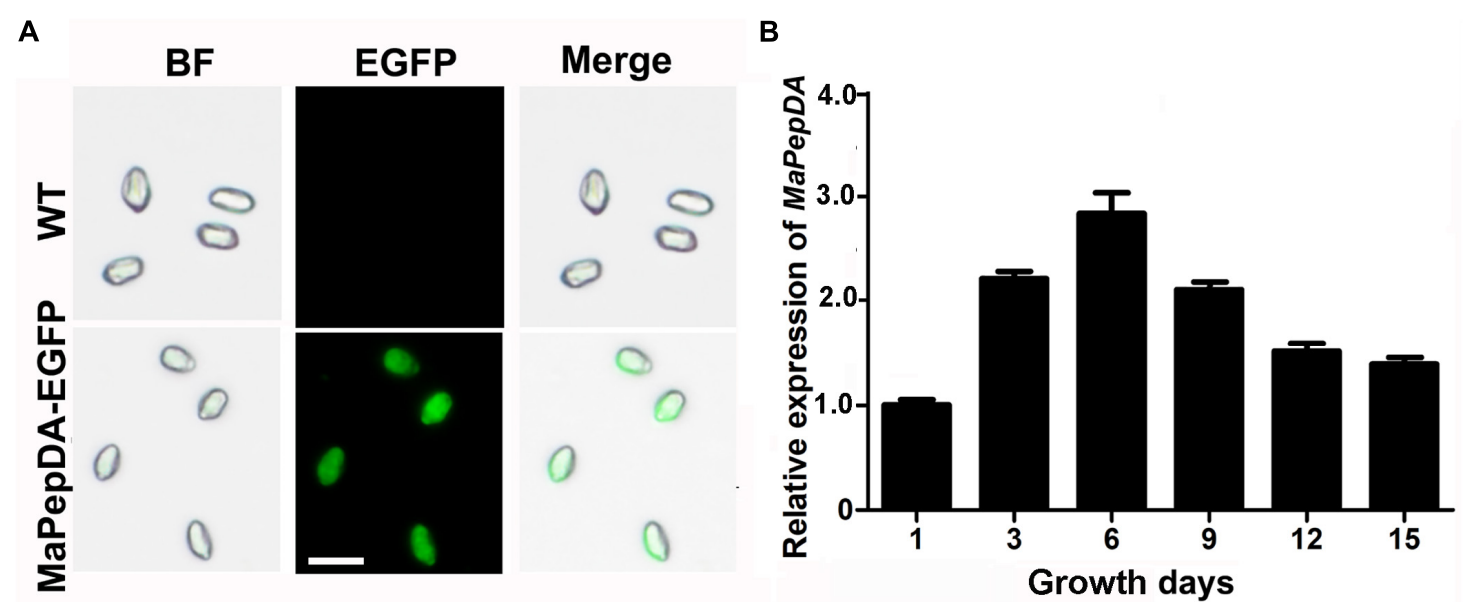

FIGURE 2 | Subcellular localization of MaPepDA and the transcription of MaPepDA in M. acridum. (A) Subcellular localization of MaPepDA. BF, bright field. Bars indicate $5 \mu \mathrm{m}$. (B) Transcription of MaPepDA in different growth period. The transcription level of MaPepDA on the first growth day was designed as 1 and transcription on other days were compared with the first growth day.

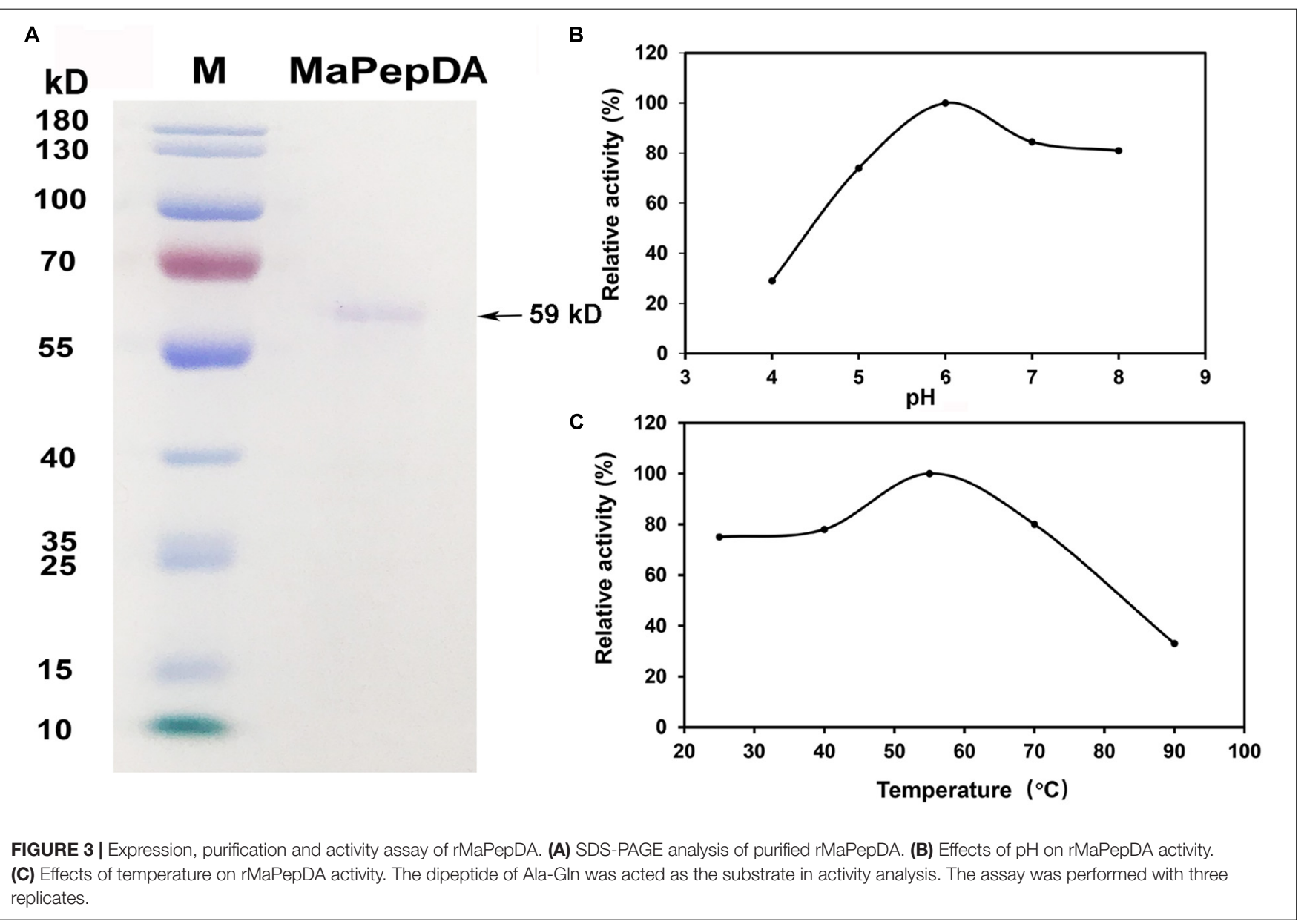

at $25^{\circ} \mathrm{C}$ and $70^{\circ} \mathrm{C}$, respectively, but decreased rapidly with the increasing temperature up to $90^{\circ} \mathrm{C}$ (Figure 3C).

To explore the substrate specificity and activity of MaPepDA, the purified enzyme solution was incubated with different substrates, Ala-Gln, Leu-Phe, and Gly-Pro, at various concentrations. Enzyme activity of MaPepDA was quantified using the Cd-ninhydrin assay after the hydrolysis of dipeptides. Judging from $K_{\mathrm{m}}$ values in Table 1, MaPepDA had a higher 
TABLE 1 | Substrate specificity and kinetic parameter of MaPepDA.

\begin{tabular}{lccc}
\hline Substrate & Enzyme activity (U/mg) & Relative activity & $\boldsymbol{K}_{\mathbf{m}}(\mathbf{m M})$ \\
\hline Ala-GIn & 240 & $100 \%$ & 1645 \\
Leu-Phe & 132 & $54 \%$ & 186 \\
Gly-Pro & 47 & $19 \%$ & 768 \\
\hline
\end{tabular}

substrate affinity for Leu-Phe (186 mM), followed by GlyPro $(768 \mathrm{mM})$ and Ala-Gln $(1645 \mathrm{mM})$. Substrate specificity analysis showed that MaPepDA had $240 \mathrm{U} / \mathrm{mg}$ activity toward Ala-Gln, $132 \mathrm{U} / \mathrm{mg}$ toward Leu-Phe, and $47 \mathrm{U} / \mathrm{mg}$ toward Gly-Pro (Table 1).

\section{Deletion and Complementation of the MaPepDA Gene}

In order to analyze the functions of MaPepDA in $M$. acridum, the $\triangle M a P e p D A$ mutant was generated by homologous recombination, in which the $M a P e p D A$ open reading frame (ORF) was replaced by a bar gene (Supplementary Figure S1A).

The MaPepDA gene was complemented by random inserting a functional copy. The complementation plasmid was carrying MaPepDA native promoter and an EGFP fusion gene (Supplementary Figure S1A). PCR (Supplementary Figure S1B) and Southern blot (Supplementary Figure S1C) confirmed that the $\triangle M a P e p D A$ strain had correctly inserted the Bar disruption cassette. The hybridizing band was about $2.6-\mathrm{kb}$ in WT, 3.3-kb in mutant, and 2.6 and 3.3-kb bands both appeared in $\mathrm{CP}$ strain, indicating that the $M a P e p D A$ gene was targeted disrupted (Supplementary Figure S1C).

\section{MaPepDA Had a Crucial Role in Conidial Germination and Hyphae Growth}

Growth on plate showed that the colony diameter of the $\triangle M a P e p D A$ mutant obviously increased compared with WT and $\mathrm{CP}$ (Figure 4A). $\triangle M a P e p D A$ mutant had much longer and more densely aerial hyphae compared with the WT (Figure 4A).

The conidia of $\triangle M a P e p D A$ mutant germinated at $4 \mathrm{~h}$, while most WT and CP conidia were still intact, suggesting an accelerated conidial germination in $\triangle M a P e p D A$ compared to $\mathrm{WT}$ and CP strains (Figure 4B). The mean 50\% germination time $\left(\mathrm{GT}_{50}\right)$ of $\triangle \mathrm{MaPepDA}(5.35 \pm 0.20 \mathrm{~h})$ was significantly decreased compared to WT $(7.10 \pm 0.06 \mathrm{~h})(P<0.01$, Figure 4C). However, time-course analysis of conidia production showed that MaPepDA didn't affect conidia yield in M. acridum (Supplementary Figure S2).

\section{Disruption of the MaPepDA Gene Enhanced Heat-Shock Tolerance}

In order to estimate the survival under natural stress, the fungal tolerance to heat-shock was analyzed. A time-course study of heat-treatment showed that the conidial germination of WT was significantly lower than $\triangle M a P e p D A(P<0.01$; Figure 5A). The mean $50 \%$ inhibition time $\left(\mathrm{IT}_{50}\right)$ of $\triangle M a P e p D A$ was $8.98 \pm 0.99 \mathrm{~h}$, significantly increased compared to WT and $\mathrm{CP}$, which were $4.76 \pm 0.54 \mathrm{~h}$ and $4.89 \pm 0.19 \mathrm{~h}$, respectively $(P<0.01$; Figure 5B).

The fungal germination was examined under microscope for the 6-h treatment group. Figure 5C showed that a substantial number of spores the $\triangle M a P e p D A$ conidia germinated and produced long hyphae, while most WT and CP conidia still do not have a discernible germ tube. These results suggested that disruption of the MaPepDA increased tolerance to heat shock in M. acridum.

\section{MaPepDA Negatively Regulates UV-B Tolerance}

Ultraviolet radiation is one of the most important factors influencing the conidia survival. Therefore, the UV-B tolerance was evaluated in strains of $\triangle M a P e p D A$, WT and CP. After exposed to UV-B irradiation for a period of time, conidial germination was analyzed after growing for $20 \mathrm{~h}$. The $\triangle M a P e p D A$ mutant had $40 \%$ and $18 \%$ germination after $3 \mathrm{~h}$ and $4.5 \mathrm{~h}$ of UV-B treatment, respectively, which was significantly higher than that of WT (17\% and $8 \%$, respectively) $(P<0.01$, Figure 6A). Microscope observation of conidial and hyphal morphology at $4.5 \mathrm{~h}$ showed that WT and CP strains had tiny germ tubes, while $\triangle M a P e p D A$ conidia generated much longer hyphae (Figure 6A). The $\mathrm{IT}_{50}$ of $\triangle M a P e p D A$ was $3.00 \pm 0.20 \mathrm{~h}$, significantly increased compared to WT and CP, which were $1.99 \pm 0.05 \mathrm{~h}$ and $2.41 \pm 0.14 \mathrm{~h}$, respectively $(P<0.01$
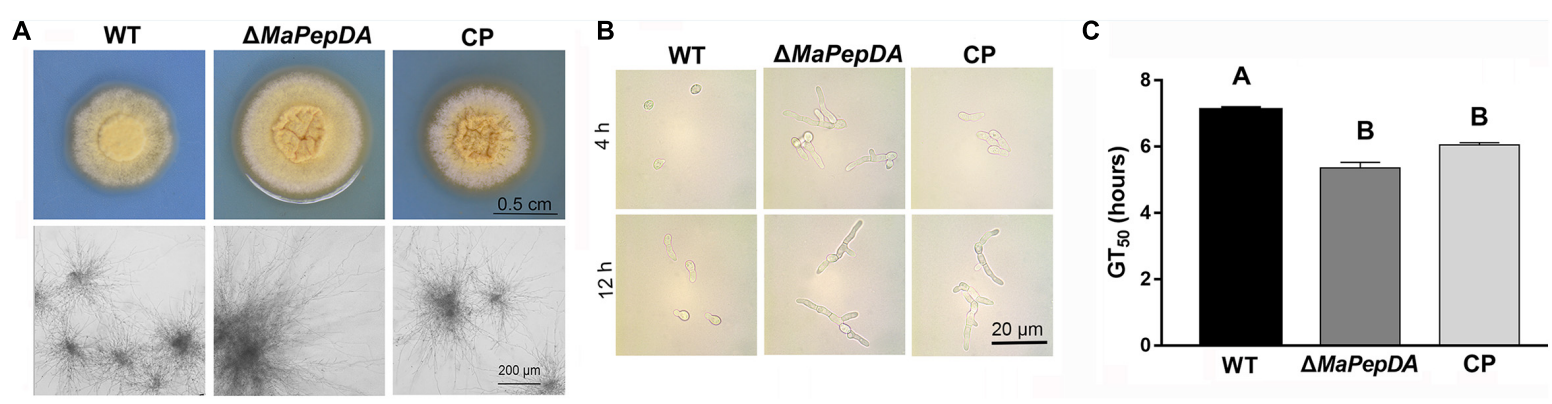

FIGURE 4 | The MaPepDA was essential for conidial germination and hyphae polarized growth. (A) Colony morphology and hyphae growth on 1/4 SDAY. (B) Germination of three strains at $4 \mathrm{~h}$ and $12 \mathrm{~h}$ post inoculation. (C) The mean $50 \%$ germination time (GT 50$)$ of fungal strains. Different capital letters denote significant differences at $p<0.01$. 


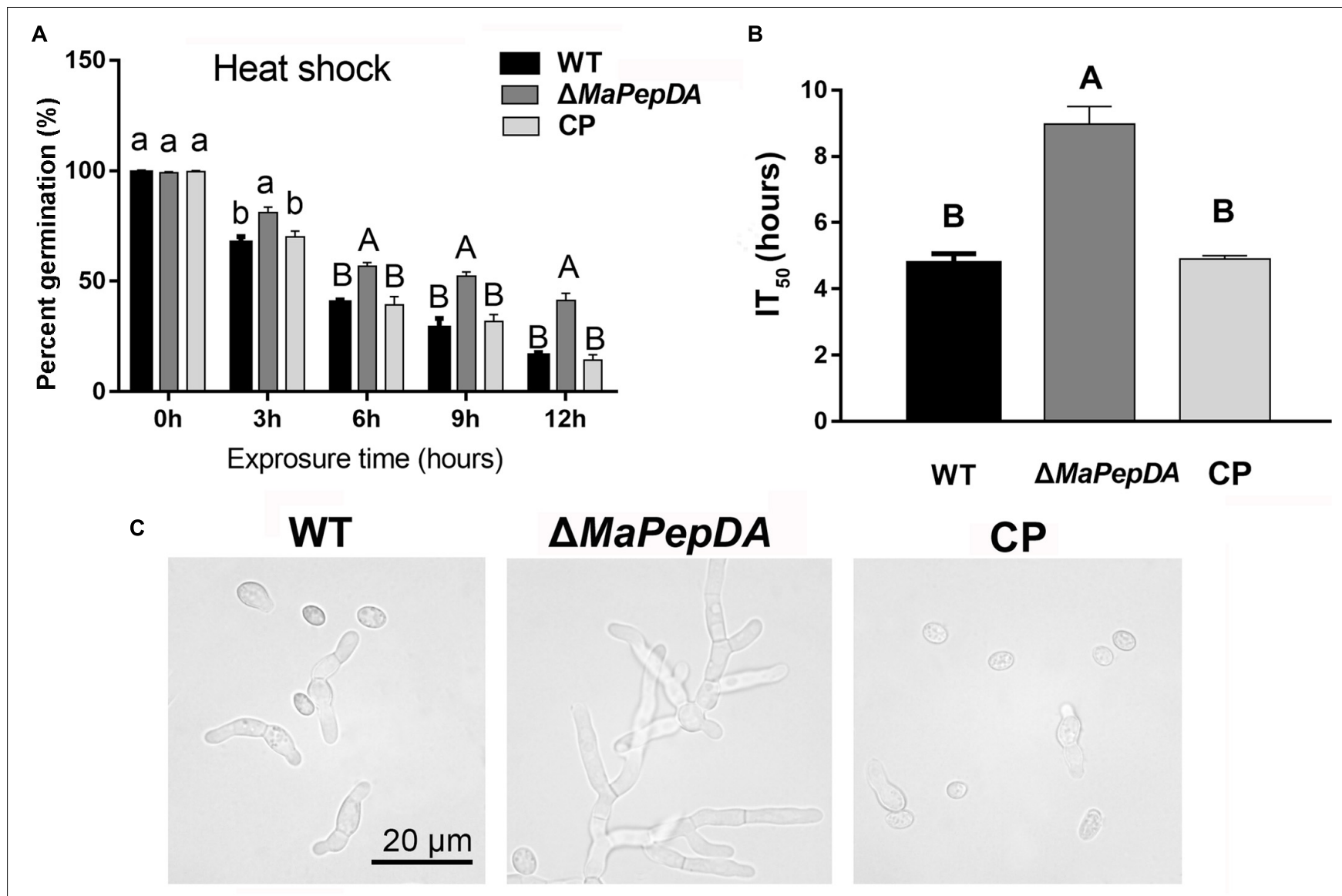

FIGURE 5 | The MaPepDA negatively controlled fungal tolerances to heat shock. (A) Conidial germination was counted after exposure to $45^{\circ} \mathrm{C}$ for 3,6 , 9 , and 12 h. All strains were then cultured on $1 / 4$ SDAY medium at $28^{\circ} \mathrm{C}$ for $20 \mathrm{~h}$. (B) The mean $50 \%$ inhibition time $\left(\mathrm{IT}_{50}\right)$ under heat shock. Different capital letters denote significant differences at $p<0.01$. (C) Conidial germination was photographed after exposure to $45^{\circ} \mathrm{C}$ for $6 \mathrm{~h}$, followed by culturing at $28^{\circ} \mathrm{C}$ for $20 \mathrm{~h}$.

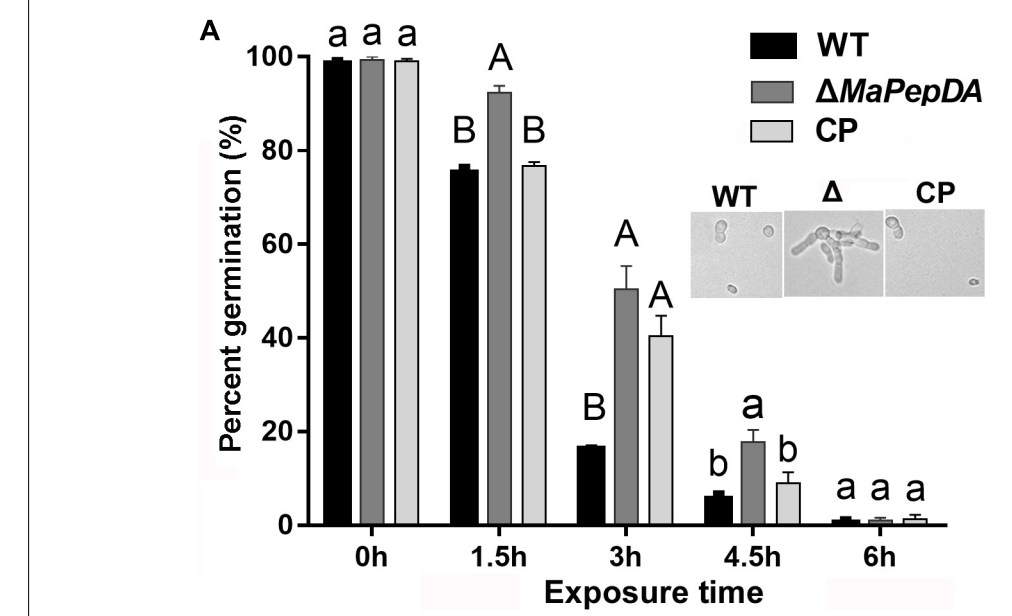

B

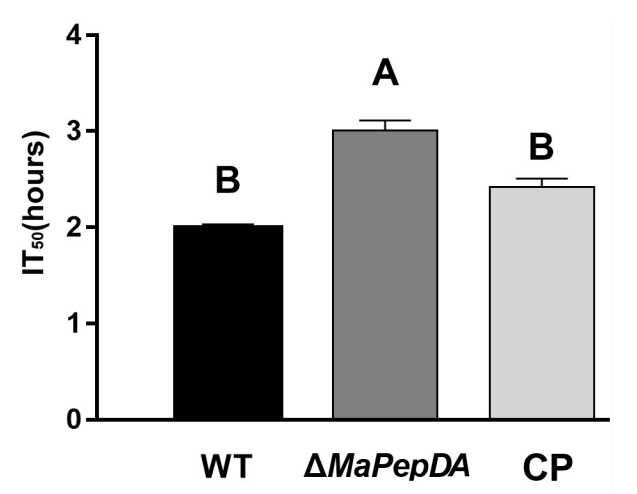

FIGURE 6 | The MaPepDA negatively regulated tolerance to UV-B irradiation. (A) Conidial germination rate was counted after exposure to UV-B irradiation $\left(1350 \mathrm{~mW} / \mathrm{m}^{2}\right)$ for $1.5,3,4.5$, and $6 \mathrm{~h}$. Upper diagram in panel A showed the conidial germination after exposure to UV-B irradiation for $4.5 \mathrm{~h}$. All strains were then cultured on $1 / 4$ SDAY medium at $28^{\circ} \mathrm{C}$ for $20 \mathrm{~h}$. (B) IT $\mathrm{T}_{50}$ under UV-B irradiation. Capitalized letter: significant difference, $p<0.01$; lowercase letter: significant difference, $p<0.05$. 


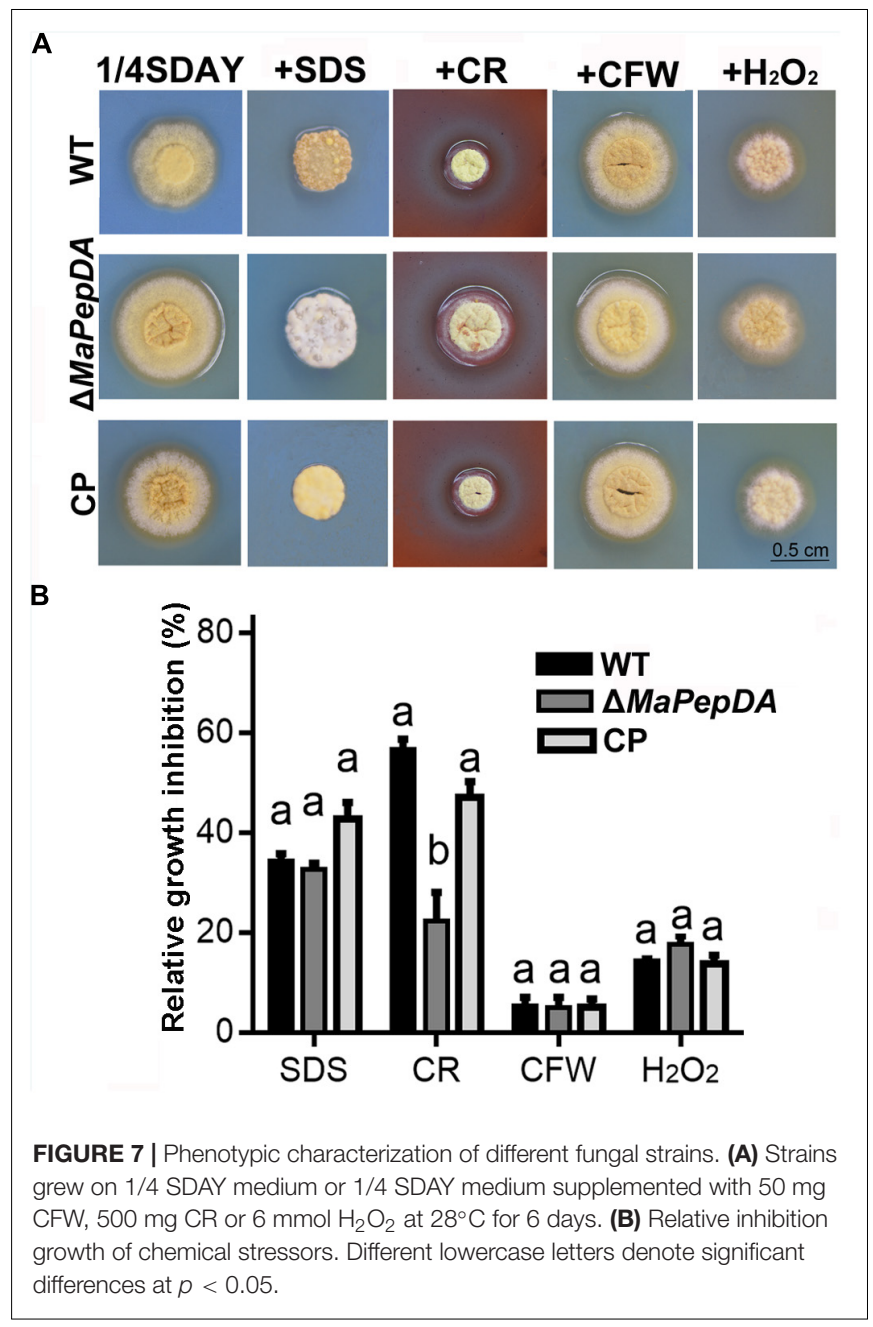

Figure 6B). These results suggested that the MaPepDA gene negatively affected the tolerance to UV-B stress.

\section{The MaPepDA Affects the Tolerance of Cell Wall-Disturbing Agents}

Spot assays were performed to investigate the sensitivity of fungal strains to cell wall disturbing agents (Figure 7A). $\triangle M a P e p D A$ had $22.3 \%$ RGI when CR was included in the medium, significantly lower than WT and CP strains $(P<0.05)$, which were $56.7 \%$ and $47.1 \%$, respectively (Figure $7 B$ ). However, the RGI of $\triangle M a P e p D A$ had no significant difference with WT and CP under SDS, $\mathrm{H}_{2} \mathrm{O}_{2}$ and CFW stressors $(P>0.05$, Figure 7B).

\section{MaPepDA Had No Effect on Virulence in M. acridum}

To evaluate the contribution of the MaPepDA to virulence in $M$. acridum, we conducted pathogenicity assay by applying conidia topically on pronotum (Supplementary Figure S3A) or injected (Supplementary Figure S3B) into the hemolymph of L. migratoria manilensis with conidia suspensions of WT, $\triangle M a P e p D A$ and CP strains. Results showed that the $\triangle M a P e p D A$ did not affect virulence in $M$. acridum. There was no difference in $\mathrm{LT}_{50}$ among WT, $\triangle M a P e p D A$, and CP strains both in topical assay $(P>0.05$, Supplementary Figure S3C) or injection assay $(P>0.05$, Supplementary Figure S3D).

\section{Identification of DEGs Regulated by the MaPepDA}

In order to further explore the mechanism of the MaPepDA gene in regulating the stress resistance and growth, RNA-seq was performed to compare the differentially expressed genes between $\triangle M a P e p D A$ and WT. RNA-seq analysis mapped 9761 transcripts of the $M$. acridum genes. Differential expression analysis identified 132 transcripts with significant expression changes ( $p \leq 0.05$ and fold change $\geq 2$ ). RNA-seq revealed that 98 transcripts were commonly up-regulated and 34 transcripts were down-regulated. Gene ontology (GO) based enrichment analysis was carried out using a threshold value $(p \leq 0.05)$. GO annotation suggested that the DEGs were divided into three categories with 106 in molecular function, 54 in biological process, and 80 in cellular component (Figure $\mathbf{8 A}$ ). The classification results (Supplementary Table S3) showed that these functional differential genes were mainly involved in multiple life processes such as growth (20 genes), sporulation (3 genes), cell wall components (11 genes), DNA damage repair (4 genes), stress tolerance (12 genes), amino acid metabolism (10 genes), sugar metabolism and transportation (5 genes), and some important signaling pathways.

In order to analyze the reliability of digital expression profiling, 24 DEGs were selected for qRT-PCR analysis to verify the RNA-seq results. Twenty-three genes showed similar expression patterns in both qRT-PCR and RNA-seq analysis except for one gene (MAC_03493), indicating that the RNA-seq data was reliable (Figure 8B).

\section{DISCUSSION}

At present, the research of dipeptidase mainly focuses on animal (O’Dwyer et al., 2009; Andreyeva et al., 2019; Choudhury et al., 2019), human pathogenic bacteria (Chang et al., 2010; Toyotome et al., 2015) or plant pathogenic bacteria (Kumar et al., 2014). Function reports of dipeptidases are mostly limited to virulence and growth in microorganisms, while there is little information regarding the effect of dipeptidases on stress tolerance in microorganisms. Family C69 dipeptidase is strictly distributed in fungi to ascomycetes (Rawlings and Bateman, 2019). Few studies were reported on PepDA in microorganisms and no functional analysis has been reported in fungi.

Peptidases produced by periodontopathic bacteria provide nutrients for bacterial growth, and are important etiologic reagents involved in degradation of periodontal tissues and alterations of the host immune system and bioactive peptides (Potempa et al., 2000). Our biochemical data confirmed that the MaPepDA had broad substrate specificity and could efficiently hydrolyze dipeptides to single amino acid, even toward the hard-to-degrade Gly-Pro sequence. This characteristic 

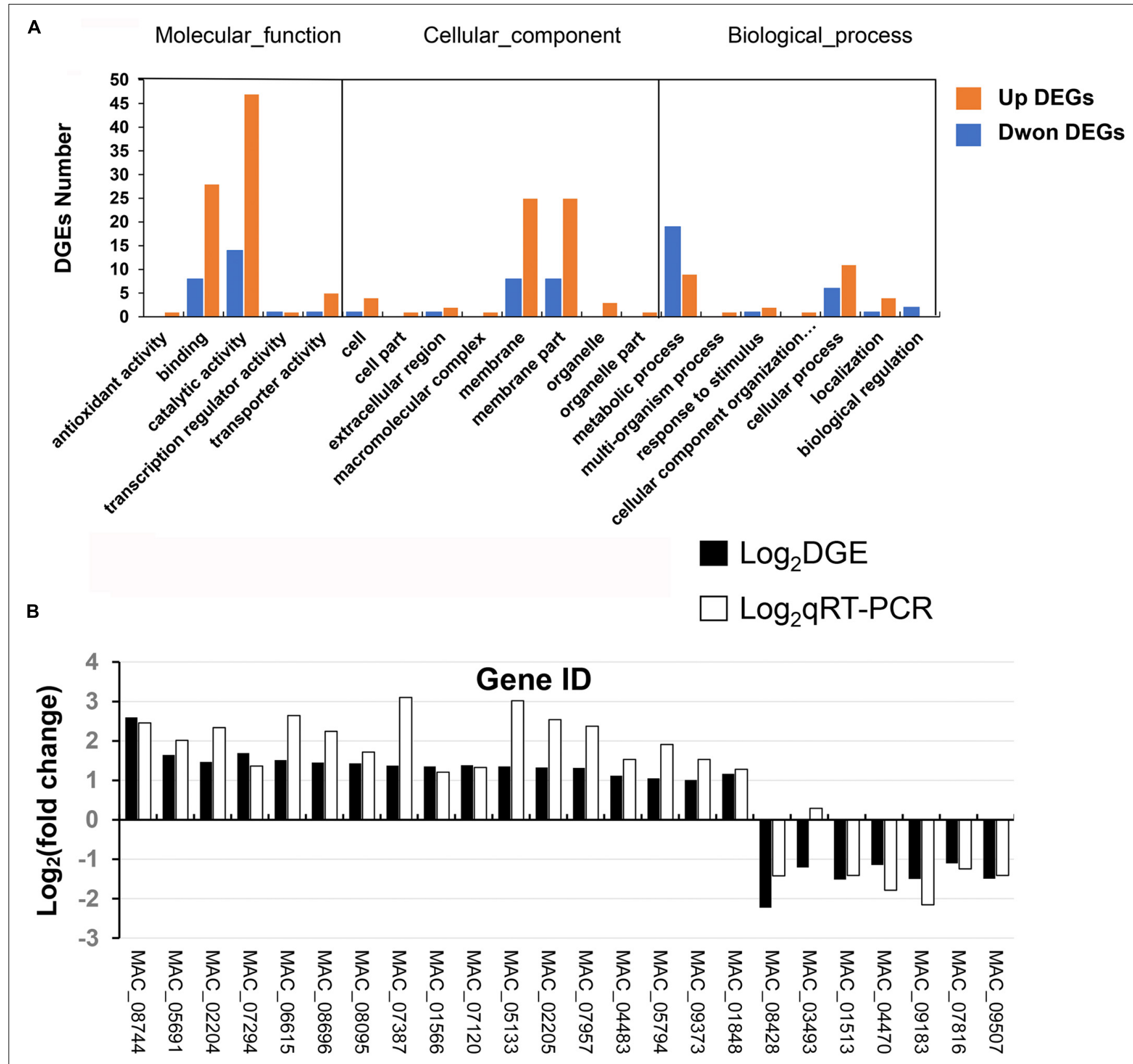

FIGURE 8|RNA_seq analysis. (A) GO annotation of differentially expressed genes. (B) qRT-PCR analysis to verify RNA_seq results.

of Gly-Pro degrading is also rare for bacterial dipeptidase (Sakamoto et al., 2013). Consistent with bacterial PepDA (Sakamoto et al., 2013), MaPepDA had a high affinity to the substrate Ala-Gln and a strong tolerance to high temperature. MaPepDA has similar enzymological characteristics as in bacteria, indicating that PepDA was conservative in biochemical properties in different microorganisms.

During the infection process, entomopathogenic fungi secret many proteinases to degrade the insect cuticle. Previous reports showed that peptidases were mostly secreted outside and some peptidases played certain roles in virulence in entomopathogenic fungi (St. Leger, 1995; St. Leger et al., 1997). However, there is no report about the function of dipeptidases on virulence of pathogens. Our study showed that MaPepDA did not affect virulence in $M$. acridum. As an intracellular peptidase, MaPepDA might diverge in function in virulence due to the different subcellular location from other peptidases. MaPepDAEGFP fusion expression showed that MaPepDA was diffused in cytoplasm and expressed during the whole fungal growth, suggesting a role of MaPepDA in growth. Consistent with the expression results, fungal growth analysis demonstrated that MaPepDA negatively regulated fungal growth. Also, RNA_seq results showed that many genes related amino acid metabolism were up-regulated (Supplementary Table S2) in $\triangle M a P e p D A$, 
which might balance the changes of protein metabolism when MaPepDA was inactivated. For example, carboxypeptidase (MAC_08739), a similar function as the virulence factor Pr1 (St. Leger et al., 1994), was upregulated in $\triangle M a P e p D A$.

Unlike no influence of PepDA on growth in bacteria (Sakamoto et al., 2013), $\triangle M a P e p D A$ mutant had an increased growth and earlier conidial germination compared to WT strain, suggesting a functional diversity of PepDA in different organisms. Consistent with the changes of phenotype, RNAseq data showed that some genes related to fungal growth and germination were up-regulated in $\triangle M a P e p D A$. SpoC1-C1C (MAC_08744), a conidial specific transcriptional activator, was up-regulated in $\triangle M a P e p D A$, which was reported highly expressed during the conidial germination and the mycelial growth in Aspergillus nidulans (Stephens et al., 1999). Fatty acid metabolism-related gene 3,2-trans-enoyl-CoA isomerase precursor (MAC_05794), which affected the growth in yeast (Gurvitz et al., 1998), had doubled transcription when the MaPepDA was impaired. Up-regulated cytochrome P450 genes (MAC_07120, MAC_07845) in $\triangle M a P e p D A$ were reported to contribute to polarized growth and conidiogenesis in Fusarium graminearum (Shin et al., 2017). Nine of ten DEGs related to amino acid metabolism were up-regulated when the MaPepDA was disrupted, which was consistent with the more active growth in $\triangle M a P e p D A$.

When applied in the field, the two detrimental environmental stresses, heat and UV-irradiation, can kill the conidia, which limits the ability of fungi to survive and infect hosts in the environment, and also affect the proliferation and dispersion of fungi (Fernandes et al., 2015; Ortiz-Urquiza and Keyhani, 2015; Rangel et al., 2015). Our study showed that disruption of the $M a P e p D A$ gene significantly improved the fungal resistance to UV-B, heat-shock and chemical stresses. Transcription data suggested that disruption of the MaPepDA triggered upregulation of some genes related to different stress tolerance, such as genes involved in DNA damage repair and cell wall proteins. Indole-diterpene biosynthesis protein PaxU (MAC_01848) was defined as a DNA repair protein RAD57 in KEGG (K10958), which was required for genetic recombination and DNA repair (Sung, 1997). A/G-specific adenine glycosylase (MAC_09373) was reported to be involved in DNA damage repair processes, repairing $\mathrm{A} / \mathrm{G}$ in DNA and A/8-oxoG mismatches in E. coli ( $\mathrm{Lu}$, 2000). MAC_09373 was up-regulated in a protein phosphatase gene MaPpt mutant in M. acridum. Similar as MaPepDA, the MaPpt gene is also a negative regulator of UV stress tolerance (Zhang et al., 2019). Aspartate aminotransferase (MAC_08901), defined as a Xeroderma pigmentosum group C-complementing protein in KEGG (K10958), was involved in the main process of removing UV damage and many chemical lesions from DNA (Jones and Wood, 1993). In yeast, the cysteine-rich protein (MAC_07294) activated the transcription of metallothionein genes (MT) (Szczypka and Thiele, 1989), which bound heavy metal, scavenged free radicals, and protected DNA from radiation damage (Jie et al., 2005). In plant cell, the transcription level of 4-coumarate-CoA ligase (MAC_07387) was increased after UV irradiation, playing a crucial role in protection from UV radiation (Kuhn et al., 1984; Mierziak et al., 2014).

Cell wall proteins are involved in fungal cell wall integrity and are also critical for stress tolerance. The cell wall protein ecm33 mutant displayed hypersensitivity to temperature in Candida albicans (Gil-Bona et al., 2016). Our results demonstrated that two cell wall proteins (MAC_02204, MAC_05133) were up-regulated in $\triangle M a P e p D A$, possibly beneficial for the increased stress tolerance of the mutant strain. Glycosylphosphatidylinositol metabolism was involved in heat tolerance in S. cerevisiae (Nasution et al., 2015). Inositol monophosphatase (MAC_04535) played a key role in the phosphatidylinositol signaling pathway (Goswami et al., 2018). Up-regulation of inositol monophosphatase might contribute to the increased heat tolerance in $M a P e p D A$ null mutant. Chitinases, up-regulated in $\triangle M a P e p D A$ (MAC_02205), have also displayed important roles in thermal stress tolerance in yeast (Versele and Thevelein, 2001) and M. anisopliae (Staats et al., 2013).

The RTA1 domain protein (MAC_01513) and catalase (MAC_04470) genes were down-regulated in $\triangle M a P e p D A$ (Supplementary Table S2). In yeast, the cysteine-rich protein activated the transcription of metallothionein genes (MT) (Szczypka and Thiele, 1989), which bound heavy metal, scavenged free radicals, and protected DNA from radiation damage, thereby increasing the strain's UV-B tolerance (Jie et al., 2005). In S. cerevisiae, the RTA1 domain protein was involved in the regulation of strain resistance, which led to strong resistance of S. cerevisiae to inhibitors and stimulation (Soustre et al., 1996).

\section{CONCLUSION}

In conclusion, our results showed the characteristics of a typical C69-family cysteine dipeptidase in M. acridum. Biological function analysis demonstrated that disruption of the MaPepDA resulted in increased conidial germination, growth rate, and significantly improved the tolerance to UV-B and thermal stress compared to WT. Since UV and thermal stress susceptibilities represent the important potential limitation to the practical application of fungal bio-agents in field, further manipulations, such as engineered techniques, may be attempted on PepDA to potentially improve the efficiency in field application of entomopathogenic fungi.

\section{DATA AVAILABILITY STATEMENT}

The datasets generated for this study can be found in the PRJNA540381.

\section{AUTHOR CONTRIBUTIONS}

JL conducted the main experiment and wrote the manuscript. MG conducted RNA transcription. JL and YC analyzed the 
data. YX and YC conceived and designed the experiments. YX and YC provided technical oversight and critical manuscript review and editing.

\section{FUNDING}

This was supported by the National Key R\&D Program of China (Grant No. 2017YFD0201200), Natural Science Foundation of China (Grant No. 31272090), Program for Innovation

\section{REFERENCES}

Andreyeva, E. N., Ogienko, A. A., Dubatolova, T. D., Oshchepkova, A. L., Kozhevnikova, E. N., Ivankin, A. V., et al. (2019). A toolset to study functions of Cytosolic non-specific dipeptidase 2 (CNDP2) using Drosophila as a model organism. BMC Genet. 20(Suppl. 1):31. doi: 10.1186/s12863-019-0726-z

Audic, S., and Claverie, J. M. (1997). The significance of digital gene expression profiles. Genome Res. 7, 986-995. doi: 10.1101/gr.7.10.986

Aw, K. M. S., and Hue, S. M. (2017). Mode of Infection of Metarhizium spp. fungus and their potential as biological control agents. J. Fungi 3, 30. doi: 10.3390/jof3020030

Barrett, A. J. (1994). Classification of peptidases. Methods Enzymol. 244, 1-15. doi: 10.1016/0076-6879(94)44003-4

Barrett, A. J., and Rawlingsm, N. D. (2013). "Introduction: the clans and families of cysteine peptidases," in Handbook of Proteolytic Enzymes, eds A. J. Barrett, N. D. Rawlings, and J. F. Woessner (Cambridge, MA: Academic Press), 1743-1773.

Beauvais, A., Monod, M., Wyniger, J., Debeaupuis, J. P., Grouzmann, E., Brakch, N., et al. (1997). Dipeptidyl-peptidase IV secreted by Aspergillus fumigatus, a fungus pathogenic to humans. Infect. Immun. 65, 3042-3047. doi: 10.1128/iai. 65.8.3042-3047.1997

Braga, G. U., Rangel, D. E., Fernandes, E. K., Flint, S. D., and Roberts, D. W. (2015). Molecular and physiological effects of environmental UV radiation on fungal conidia. Curr. Genet. 61, 405-425. doi: 10.1007/s00294-015-0483-0

Brunner-Mendoza, C., Reyes-Montes, M. D. R., Moonjely, S., Bidochka, M. J., and Toriello, C. (2019). A review on the genus Metarhizium as an entomopathogenic microbial biocontrol agent with emphasis on its use and utility in Mexico. Biocontrol Sci Techn. 29, 83-102. doi: 10.1080/09583157.2018. 1531111

Cao, Y., Du, M., Luo, S., and Xia, Y. (2014). Calcineurin modulates growth, stress tolerance, and virulencein in Metarhizium acridum and its regulatory network. Appl. Microbiol. Biotechnol. 98, 8253-8265. doi: 10.1007/s00253-014-5876-3

Chang, C. Y., Hsieh, Y. C., Wang, T. Y., Chen, Y. C., Wang, Y. K., Chiang, T. W., et al. (2010). Crystal structure and mutational analysis of aminoacylhistidine dipeptidase from Vibrio alginolyticus reveal a new architecture of M20 metallopeptidases. J. Biol. Chem. 285, 39500-39510. doi: 10.1074/jbc.M110. 139683

Choudhury, S. R., Babes, L., Rahn, J. J., Ahn, B. Y., Goring, K. R., King, J. C., et al. (2019). Dipeptidase-1 is an adhesion receptor for neutrophil recruitment in lungs and liver. Cell 178, 1205-1221. doi: 10.1016/j.cell.2019.07.017

Clarke, S. C., Dumesic, P. A., Homer, C. M., O’Donoghue, A. J., La Greca, F., Pallova, L., et al. (2016). Integrated activity and genetic profiling of secreted peptidases in Cryptococcus neoformans reveals an aspartyl peptidase required for low $\mathrm{pH}$ survival and virulence. PLoS Pathog. 12:e1006051. doi: 10.1371/ journal.ppat.1006051

de Oliveira, T. B., Gostincar, C., Gunde-Cimerman, N., and Rodrigues, A. (2018). Genome mining for peptidases in heat-tolerant and mesophilic fungi and putative adaptations for thermostability. BMC Genomics 19:152. doi: 10.1186/ s12864-018-4549-5

dos Reis, M. C., Pelegrinelli, F. M. H., Delgado Duarte, R. T., Furlaneto, L., and Furlaneto, M. C. (2004). Agrobacterium tumefaciens-mediated genetic transformation of the entomopathogenic fungus Beauveria bassiana. J. Microbiol. Methods 58, 197-202. doi: 10.1016/j.mimet.2004.03.012

dos Santos, A. L., de Carvalho, I. M., da Silva, B. A., Portela, M. B., Alviano, C. S., de Araújo, R. M. S., et al. (2006). Secretion of serine peptidase by a clinical strain of
Research Group in Colleges and Universities of Chongqing (CXQTI19004), and Natural Science Foundation Project of CQ CSTC (cstc2018jcyjAX0204).

\section{SUPPLEMENTARY MATERIAL}

The Supplementary Material for this article can be found online at: https://www.frontiersin.org/articles/10.3389/fmicb. 2020.00849/full\#supplementary-material

Candida albicans: influence of growth conditions and cleavage of human serum proteins and extracellular matrix components. FEMS Immunol. Med. Microbiol. 46, 209-220. doi: 10.1111/j.1574-695x.2005.00023.x

Dudley, E. G., Husgen, A. C., He, W., and Steele, J. L. (1996). Sequencing, distribution, and inactivation of the dipeptidase A gene (pepDA) from Lactobacillus helveticus CNRZ32. J. Bacteriol. 178, 701-704. doi: 10.1128/jb. 178.3.701-704.1996

Dutton, L. C., Jenkinson, H. F., Lamont, R. J., and Nobbs, A. H. (2016). Role of Candida albicans secreted aspartyl protease Sap9 in interkingdom biofilm formation. Pathog. Dis. 74:ftw005. doi: 10.1093/femspd/ftw005

Elsoda, M., Macedo, A., Olson, N. F., and Ezzat, N. (1992). The peptide-hydrolase system of Bifidobacterium species. Milchwissenschaft 47, 87-90.

Fernandes, E. K., Rangel, D. E., Braga, G. U., and Roberts, D. W. (2015). Tolerance of entomopathogenic fungi to ultraviolet radiation: a review on screening of strains and their formulation. Curr. Genet. 61, 427-440. doi: 10.1007/s00294015-0492-z

Folkertsma, B., and Fox, P. F. (1992). Use of the Cd-ninhydrin reagent to assess proteolysis in cheese during ripening. J. Dairy Res. 59, 217-224. doi: 10.1017/ s0022029900030466

Gil-Bona, A., Reales-Calderon, J. A., Parra-Giraldo, C. M., Martinez-Lopez, R., Monteoliva, L., and Gil, C. (2016). The cell wall protein Ecm33 of Candida albicans is involved in chronological life span, morphogenesis, cell wall regeneration, stress tolerance, and host-cell interaction. Front. Microbiol. 7:64. doi: $10.3389 /$ fmicb.2016.00064

Gobbetti, M., and Fox, P. F. (1998). Purification and characterization of a dipeptidase from Pseudomonas fluorescens ATCC 948. J. Food Biochem. 22, 17-35. doi: 10.1111/j.1745-4514.1998.tb00228.x

Goswami, R., Bondoc, J. M. G., Wheeler, P. R., Jafari, A., Gonzalez, T., Mehboob, S., et al. (2018). Inositol monophosphatase: a bifunctional enzyme in Mycobacterium smegmatis. ACS Omega 3, 13876-13881. doi: 10.1021/ acsomega.8b01753

Greenfield, M., Gómez-Jiménez, M. I., Ortiz, V., Vega, F. E., Kramer, M., and Parsa, S. (2016). Beauveria bassiana and Metarhizium anisopliae endophytically colonize cassava roots following soil drench inoculation. Biol. Control. 95, 40-48. doi: 10.1016/j.biocontrol.2016.01.002

Guerrero-Guerra, C., Reyes-Montes, M. M. R., Toriello, C., Hernández-Velázquez, V., Santiago-López, I., et al. (2013). Study of the persistence and viability of Metarhizium acridum in Mexico's agricultural area. Aerobiologia 29, 249-261. doi: 10.1007/s10453-012-9277-8

Gurvitz, A., Mursula, A. M., Firzinger, A., Hamilton, B., Kilpeläinen, S. H., Hartig, A., et al. (1998). Peroxisomal Delta3-cis-Delta2-trans-enoyl-CoA isomerase encoded by ECI1 is required for growth of the yeast Saccharomyces cerevisiae on unsaturated fatty acids. J. Biol. Chem. 273, 31366-31374. doi: 10.1074/jbc. 273.47.31366

Hamin Neto, Y. A. A., da Rosa Garzon, N. G., Pedezzi, R., and Cabral, H. (2018). Specificity of peptidases secreted by filamentous fungi. Bioengineered 9, 30-37. doi: 10.1080/21655979.2017.1373531

Hanes, C. S. (1983). The effect of starch concentration upon the velocity of hydrolysis by the amylase of germinated barley. Biochem. J. 26, 1406-1421.

Hong, M., Peng, G., Keyhani, N. O., and Xia, Y. (2017). Application of the entomogenous fungus, Metarhizium anisopliae, for leafroller (Cnaphalocrocis medinalis) control and its effect on rice phyllosphere microbial diversity. Appl. Microbiol. Biotechnol. 101, 6793-6807. doi: 10.1007/s00253-0178390-6 
Hu, X., Xiao, G., Zheng, P., Shang, Y., Su, Y., Zhang, X., et al. (2014). Trajectory and genomic determinants of fungal-pathogen speciation and host adaptation. Proc. Natl. Acad. Sci. U.S.A. 111, 16796-16801. doi: 10.1073/pnas.1412662111

James, M. N. (2006). The peptidases from fungi and viruses. Biol. Chem. 387, 1023-1029.

Jesper, B., Eva, N. F., and Christiaan, K. (2007). Evaluating the importance of residual effects from previous years' treatment on the efficiency of different strategies for control of Sahelian grasshoppers with Metarhizium anisopliae var. acridum. Biocontrol. Sci. Techn. 17, 413-422. doi: 10.1080/09583150701213745

Jie, L., Kaifeng, S., Dian, Y., Lin, A., and Binggen, R. (2005). Characterization of expression and stability of recombinant cystein-rich protein human MT1A from yeast. Protein Pept. Lett. 12, 567-571. doi: 10.2174/0929866054395734

Jones, C. J., and Wood, R. D. (1993). Preferential binding of the xeroderma pigmentosum group A complementing protein to damaged DNA. Biochemistry 32, 12096-12104. doi: 10.1021/bi00096a021

Kaur, H., Ganguli, D., and Bachhawat, A. K. (2012). Glutathione Degradation by the alternative pathway (DUG Pathway) in Saccharomyces cerevisiae is initiated by (Dug2p-Dug3p)2 complex, a novel glutamine amidotransferase (GATase) enzyme acting on glutathione. J. Biol. Chem. 287, 8920-8931. doi: 10.1074/jbc. M111.327411

Kuhn, D. N., Chappell, J., Boudet, A., and Hahlbrock, K. (1984). Induction of phenylalanine ammonia-lyase and 4-coumarate: CoA ligase mRNAs in cultured plant cells by UV light or fungal elicitor. Proc. Natl. Acad. Sci. U.S.A. 81, 1102-1106. doi: 10.1073/pnas.81.4.1102

Kumar, A., Are, V. N., Ghosh, B., Agrawal, U., Jamdar, S. N., Makde, R. D., et al. (2014). Crystallization and preliminary X-ray diffraction analysis of Xaa-Pro dipeptidase from Xanthomonas campestris. Acta Crystallogr. F. Struct. Biol. Commun. 70(Pt 9), 1268-1271. doi: 10.1107/S2053230X14017324

Liu, J., Cao, Y., and Xia, Y. (2010). Mmc, a gene involved in microcycle conidiation of the entomopathogenic fungus Metarhizium anisopliae. J. Invertebr. Pathol. 105, 132-138. doi: 10.1016/j.jip.2010.05.012

Livak, K. J., and Schmittgen, T. D. (2001). Analysis of relative gene expression data using real-time quantitative PCR and the 2- $\Delta \Delta \mathrm{CT}$ method. Methods 25, 402-408. doi: 10.1006/meth.2001.1262

Lu, A. L. (2000). Repair of A/G and A/8-oxoG mismatches by MutY adenine DNA glycosylase. Meth. Mol. Biol. 152:3. doi: 10.1385/1-59259-068-3:3

Marion, W., Philipp, S., Johannes, L. M. S., and Ute, M. (2016). Biological control of Ixodes ricinus larvae and nymphs with Metarhizium anisopliae blastospores. Ticks. Tick. Borne. Dis. 7, 768-771. doi: 10.1016/j.ttbdis.2016.03.010

Mierziak, J., Kostyn, K., and Kulma, A. (2014). Flavonoids as important molecules of plant interactions with the environment. Molecules 19, 16240-16265. doi: 10.3390/molecules 191016240

Milner, R. J., Lozano, L. B., Driver, F., and David, H. (2003). A comparative study of two Mexican isolates with an Australian isolate of Metarhizium anisopliae var. acridum - strain characterisation, temperature profile and virulence for wingless grasshopper. Phaulacridium vittatum. BioControl 48, 335-348.

Nahar, P., Yadav, P., Kulye, M., Hadapad, A., Hassani, M., Tuor, U., et al. (2004). Evaluation of indigenous fungal isolates, Metarhizium anisopliae M34412, Beauveria bassiana B3301 and Nomuraea rileyi N812 for the control of Helicoverpa armigera (Hübner) in pigeon pea field. J. Biol. Control. 18, 1-8.

Nasution, O., Lee, J., Srinivasa, K., Choi, I. G., Lee, Y. M., Kim, E., et al. (2015). Loss of Dfg5 glycosylphosphatidylinositol-anchored membrane protein confers enhanced heat tolerance in Saccharomyces cerevisiae. Environ. Microbiol. 17, 2721-2734. doi: 10.1111/1462-2920.12649

O'Dwyer, R., Razzaque, R., Hu, X., Hollingshead, S. K., and Wall, J. G. (2009). Engineering of cysteine residues leads to improved production of a human dipeptidase enzyme in E. coli. Appl. Biochem. Biotechnol. 159, 178-190. doi: 10.1007/s12010-008-8379-9

Ortiz-Urquiza, A., and Keyhani, N. O. (2015). Stress response signaling and virulence: insights from entomopathogenic fungi. Curr. Genet. 61, 239-249. doi: 10.1007/s00294-014-0439-9

Peng, G., Wang, Z., Yin, Y., Zeng, D., and Xia, Y. (2008). Field trials of Metarhizium anisopliae var. acridum (Ascomycota: Hypocreales) against oriental migratory locusts, Locusta migratoria manilensis (Meyen) in Northern China. Crop Prot. 27, 1244-1250. doi: 10.1016/j.cropro.2008.03.007

Potempa, J., Banbula, A., and Travis, J. (2000). Role of bacterial proteinases in matrix destruction and modulation of host responses. Periodontol. 24, 153-192. doi: $10.1034 / j .1600-0757.2000 .2240108 . x$
Rangel, D. E., Alder-Rangel, A., Dadachova, E., Finlay, R. D., Kupiec, M., Dijksterhuis, J., et al. (2015). Fungal stress biology: a preface to the fungal stress responses special edition. Curr. Genet. 61, 231-238. doi: 10.1007/s00294-0150500-3

Rangel, D. E., Braga, G. U., Anderson, A. J., and Roberts, D. W. (2005). Variability in conidial thermotolerance of Metarhizium anisopliae isolates from different geographic origins. J. Invertebr. Pathol. 88, 116-125. doi: 10.1016/j.jip.2004. 11.007

Rawlings, N. D., Barrett, A. J., and Bateman, A. (2011). Asparagine peptidelyases: a seventh catalytic type of proteolytic enzymes. J. Biol. Chem. 286, 38321-38328. doi: $10.1074 /$ jbc.M111.260026

Rawlings, N. D., and Bateman, A. (2019). Origins of peptidases. Biochimie 166, 4-18. doi: 10.1016/j.biochi.2019.07.026

Sahayaraj, K., Subash, N., Allingham, R. W., Kumar, V., Avery, P., Mehra, L., et al. (2018). Lethal and sub-lethal effects of three microbial biocontrol agents on Spodoptera litura and its natural predator Rhynocoris kumarii. Insects. 9:101. doi: 10.3390/insects9030101

Sakamoto, T., Otokawa, T., Kono, R., Shigeri, Y., and Watanabe, K. (2013). A C69family cysteine dipeptidase from Lactobacillus farciminis JCM1097 possesses strong Gly-Pro hydrolytic activity. J. Biochem. 154, 419-427. doi: 10.1093/jb/ mvt069

Semenova, T. A., Dunaevsky, Y. E., Beljakova, G. A., and Belozersky, M. A. (2020). Extracellular peptidases of insect-associated fungi and their possible use in biological control programs and as pathogenicity markers. Fungal Biol. 124, 65-72. doi: 10.1016/j.funbio.2019.11.005

Semenova, T. A., Dunaevskyb, Y. E., Beljakovaa, G. A., Borisovc, B. A., Shamraichukb, I. L., and Belozerskyb, M. A. (2017). Extracellular peptidases as possible markers of fungal ecology. Appl.Soil Ecol. 113, 1-10.

Seo, J. M., Ji, G. E., Cho, S. H., Park, M. S., and Lee, H. J. (2007). Characterization of a Bifidobacterium longum BORI dipeptidase belonging to the U34 family. Appl. Environ. Microb. 73, 5598-5606. doi: 10.1128/aem.006 $42-07$

Shin, J. Y., Bui, D. C., Lee, Y., Nam, H., Jung, S., Fang, M., et al. (2017). Functional characterization of cytochrome P450 monooxygenases in the cereal head blight fungus Fusarium graminearum. Environ. Microbiol. 19, 2053-2067. doi: 10. $1111 / 1462-2920.13730$

Soustre, I., Letourneux, Y., and Karst, F. (1996). Characterization of the Saccharomyces cerevisiae RTA1 gene involved in 7 -aminocholesterol resistance. Curr. Genet. 30, 121-125. doi: 10.1007/s002940050110

St. Leger, R. J. (1995). The role of cuticle-degrading proteases in fungal pathogenesis of insects. Can. J. Bot. 73, 1119-1125. doi: 10.1139/b95-367

St. Leger, R. J., Joshi, L., and Roberts, D. W. (1997). Adaptation of proteases and carbohydrases of saprophytic: phytopathogenic and entomopathogenic fungi to the requirements of their ecological niches. MicrobiolOGY 143, 1983-1992. doi: 10.1099/00221287-143-6-1983

St. Leger, R. J., Bidochka, M. J., and Roberts, D. W. (1994). Characterization of a novel carboxypeptidase produced by the entomopathogenic fungus Metarhizium anisopliae. Arch. Biochem. Biophys. 314, 392-398. doi: 10.1006/ abbi.1994.1458

Staats, C. C., Kmetzsch, L., Lubeck, I., Junges, A., Vainstein, M. H., and Schrank, A. (2013). Metarhizium anisopliae chitinase CHIT30 is involved in heat-shock stress and contributes to virulence against Dysdercus peruvianus. Fungal Biol. 117, 137-144. doi: 10.1016/j.funbio.2012.12.006

Stephens, K. E., Miller, K. Y., and Miller, B. L. (1999). Functional analysis of DNA sequences required for conidium-specific expression of the SpoC1-C1C gene of Aspergillus nidulans. Fungal Genet. Biol. 27, 231-242. doi: 10.1006/fgbi.1999. 1145

Steven, A., Matthew, B., and Juergen, L. (2003). Field observations of the effects of fenitrothion and Metarhizium anisopliae var. acridum on non-target ground dwelling arthropods in the Sahel. Biol. Control 26, 333-340. doi: 10.1016/s10499644(02)00166-4

Sung, P. (1997). Yeast Rad55 and Rad57 proteins form a heterodimer that functions with replication protein A to promote DNA strand exchange by Rad51 recombinase. Genes Dev. 11, 1111-1121. doi: 10.1101/gad.11.9. 1111

Szczypka, M. S., and Thiele, D. J. (1989). A cysteine-rich nuclear protein activates yeast metallothionein gene transcription. Mol. Cell Biol. 9, 421-429. doi: 10. $1128 / \mathrm{mcb} .9 .2 .421$ 
Tamura, K., Dudley, J., Nei, M., and Kumar, S. (2007). Mega4: molecular evolutionary genetics analysis (MEGA) software version 4.0. Mol. Biol. Evol. 24, 1596-1599. doi: 10.1093/molbev/msm092

Toyotome, T., Watanabe, A., Ochiai, E., and Kamei, K. (2015). N-acetylated $\alpha$ linked acidic dipeptidase is identified as an antigen of Histoplasma capsulatum. Biochem. Biophys Res. Commun. 458, 483-487. doi: 10.1016/j.bbrc.2015.01.129

Tupe, S. G., Pathan, E. K., and Deshpande, M. V. (2017). Development of Metarhizium anisopliae as a mycoinsecticide: from isolation to field performance. J. Vis. Exp. 30:55272. doi: 10.3791/55272

Versele, M., and Thevelein, J. M. (2001). Lrel affects chitinase expression, trehalose accumulation and heat resistance through inhibition of the Cbk1 protein kinase in Saccharomyces cerevisiae. Mol. Microbiol. 41, 1311-1326. doi: 10.1046/j. 1365-2958.2001.02590.x

Yike, I. (2011). Fungal proteases and their pathophysiological effects. Mycopathologia 171, 299-323. doi: 10.1007/s11046-010-9386-2

Yousef, M., Jurado, I. G., Torres, M. R., and Moraga, E. Q. (2017). Reduction of adult olive fruit fly populations by targeting preimaginals in the soil with the entomopathogenic fungus Metarhizium brunneum. J. Pest. Sci. 90, 345-354. doi: 10.1007/s10340-016-0779-y
Zhang, J., Wang, Z., Keyhani, N. O., Peng, G., Jin, K., and Xia, Y. (2019). The protein phosphatase gene MaPptl acts as a programmer of microcycle conidiation and a negative regulator of UV-B tolerance in Metarhizium acridum. Appl. Microbiol. Biotech. 103, 1351-1362. doi: 10.1007/s00253-0189567-3

Zhao, H., Lovett, B., and Fang, W. (2016). Genetically engineering entomopathogenic fungi. Adv. Genet. 94, 137-163. doi: 10.1016/bs.adgen. 2015.11.001

Conflict of Interest: The authors declare that the research was conducted in the absence of any commercial or financial relationships that could be construed as a potential conflict of interest.

Copyright (c) $2020 \mathrm{Li}$, Guo, Cao and Xia. This is an open-access article distributed under the terms of the Creative Commons Attribution License (CC BY). The use, distribution or reproduction in other forums is permitted, provided the original author(s) and the copyright owner(s) are credited and that the original publication in this journal is cited, in accordance with accepted academic practice. No use, distribution or reproduction is permitted which does not comply with these terms. 